\title{
Municipal Solid Waste(MSW) Management in Urbanization Process Based on Dynamical Model
}

\author{
Yunqiang Liu \\ College of Economics \& Management, Sichuan Agricultural University, Chengdu, \\ China \\ liuyunqiang@sicau.edu.cn
}

\begin{abstract}
It was announced by Chinese government at the Copenhagen Conference that there would be 40-45\% mitigation of the 2005 level intensity of carbon by 2020. Every industry in China is preparing to realize this national reduction target. A lot of work have been tried to achieve low-carbon development in different industries, but relatively little work has linked lowcarbon development to municipal solid waste management(MSWM). This article focuses on how to develop low-carbon MSWM using a quantitative approach. Firstly, the MSWM system including some mutual influence factors is investigated and some historical data are given in support for the research of their quantitative relationship. Secondly, a differential dynamic system model with fuzzy coefficients is proposed to predict waste amount, disposal cost, energy consumption and carbon intensity. Finally, an application to Chengdu in southwestern China, as a representative of a developed city, is presented to show the trend of MSWM in a low-carbon economy and prove the effectiveness of the proposed model.
\end{abstract}

Keywords: Municipal solid waste management(MSWM), Differential dynamic system, Low carbon economy, System simulation

\section{Introduction}

Recent studies have indicated that China is the number one contributor to carbon emissions and also a large consumer of energy [1,2]. Announcement has already been made by Chinese government that China aims to reduce the intensity of carbon per unit of GDP by $40-45 \%$ by 2020, based on 2005 levels. Due to these, low-carbon city has become one of the most important development strategies made by government to meet the requirement of the low carbon emissions and sustainable development. Municipal solid waste(MSW) management is an inevitable and challenging issue during building a low-carbon city because of its high carbon emission and energy consumption. With the continued population growth and living standards rising, MSW production is increasing and the components become more complex. A lot of carbon dioxide, methane and nitrous oxide will be emitted in MSW transportation and operation processes, and they were considered the principal components contributing to global warming. The MSW disposal industry also needs a high level of energy consumption including electricity and petrol during the total course of disposal. Therefore, the sustainable development of MSW disposal industry is currently considered to play a significant role in a low-carbon economy.

Chengdu city of Sichuan Province in China is a fast-growing city and also the eco-nomic center in western areas. With MSW production increasing rapidly caused by quick economy growth, the environment in Chengdu faces huge pressures: energy con-sumption and carbon emissions caused by MSW disposal are growing continually. With the significant growing 
life level and the associated pressure of increased volumes of MSW generation, the number of MSW disposal facilities will sharply increase and it result in the increased emissions of greenhouse gases(GHG). Some other fast-growing cities have to face the similar situation. Therefore, how to predict the MSW manage-ment(MSWM) system and how to make the policy for low-carbon MSWM system have become more important.

This paper is organized as follows: In Section 2, the literature review about MSWM system is presented. In Section 3, the MSWM system for low-carbon development is introduced and then we propose a differential dynamical system model with fuzzy coefficients for low-carbon MSWM system. In Section 4, on the basis of differential dynamic system with the subjective consciousness of human energy conservation and emission reduction, we investigate the relevant MSWM system data, including the amount of MSW, disposal cost and the number of disposal facilities in Chengdu over the past 10 years. Once we have carried out expected value operators and the fuzzy coefficients, we can get simulation results for a MSWM system. In Section 5, we make a conclusion about the effectiveness of such a model and discuss necessary further research.

\section{Literature Review}

A good deal of studies have been developed in recent decades to support decision making in MSWM and they can be divided into two categories. In the first category, the goals of the MSWM were simple and narrow, such as locating appropriate disposal facilities( collection bins, landfill or incineration plant) or optimizing waste collection routes for vehicles. Vijay et. al., for example, illustrated a geographic information system (GIS) based algorithm for optimal location and number of storage bins, consid-ering p-median constrained model, based on Indian guidelines for Municipal Solid Waste Rules [3]. The identification of a route for MSW collection facilities is critical since it has been estimated that, of the total amount of money spent for the collection, trans-portation, and disposal of solid waste, approximately 60$80 \%$ is spent on the collection phase. Therefore, a small percentage improvement in the collection operation can result to a significant saving in the overall cost. Karadimas et. al., used the Genetic Algorithm (GA) and spatio-temporal statistical analysis method to identify the most cost-effective scenario for waste collection, to estimate its running cost and to simulate its application [4]. In another category, the focus was extended to encompass MSWM on a system level, considering more interactional factors, such as system economic benefits[5, 6], environmental impacts[7-9], social factors[10].

Though a lot of studies have been taken on MSWM, saving more disposal cost and decreasing environmental pollution, not enough researches have taken low-carbon environment and greenhouse gas(GHG) emission into consideration. In recent years, some scholars made the qualitative analysis to consider the low-carbon MSWM development. For example, Muehle et. al., compared the carbon emissions associated with MSWM in Germany and the UK, and discussed potential for the UK to achieve the waste management strategy targets(focused on low-carbon objection) through increased recycling/separation and landfill legislation [11]. Pikon and Gaskatried to build proper meth-ods for assessing the environmental impact of waste management systems underpinning the development and implementation of sustainable waste management practice[12]. However, few literatures make the quantitative research for low-carbon MSWM, espe-cially in a system level. As we know,low-carbon MSWM system includes five subsystems: energy (energy subsystem), carbon emissions (emission subsystem), the amount of MSW (demand subsystem), disposal cost (demand subsystem), the number of disposal facil-ities (supply subsystem). Their quantitative relationships are important for decision makers. Therefore, a differential 
dynamical system model will be applied in this paper to quantificationally predict the trend of disposing low-carbon MSWM system.

Some scholars have done many research about the differential dynamic system model, such as, Hale [13], Park[14, 15] and Park and Kwon [16]. However, it is usually difficult to determine some coefficients in the real-life system. For example, the coefficients of energy consumption and car-bon emissions are not crisp and we only determine them by the expert's experience. Therefore, they are usually considered the fuzzy variable. Furthermore, a fuzzy differ-ential dynamic system model should be considered in MSW management system for the low-carbon development. Fuzzy differential equations (FDEs) were first formulated by Kaleva [17] and Seikkala [18]. Kaleva studied the Cauchy problem of fuzzy sets in which the Peano theorem is valid. Seikkala defined the fuzzy derivative and showed a unique solution of the deterministic initial value problem. Hukuhara derivative was used in the traditional theory of fuzzy differential equations, because the solutions of fuzzy differential equa-tions have quite different properties from those of crisp differential equations, lacking observed properties of physical systems such as stability, periodicity and bifurcation, significant problems arise with any attempt to develop formulas. This undesirable prop-erty largely was overcome by Hullermeier [19], when he proposed to interpret the fuzzy differential equation $\mathrm{x}^{L}(t)=G(t, x(t))$ as a family of differential inclusions.

\section{Modelling}

As shown in Figure 1, this model is targeted at trends in carbon emission and energy consumption of MSWM system. The main variable and the impact factor of the model are identified on the base of relevant worldwide information, as well as an analysis of other related factors.

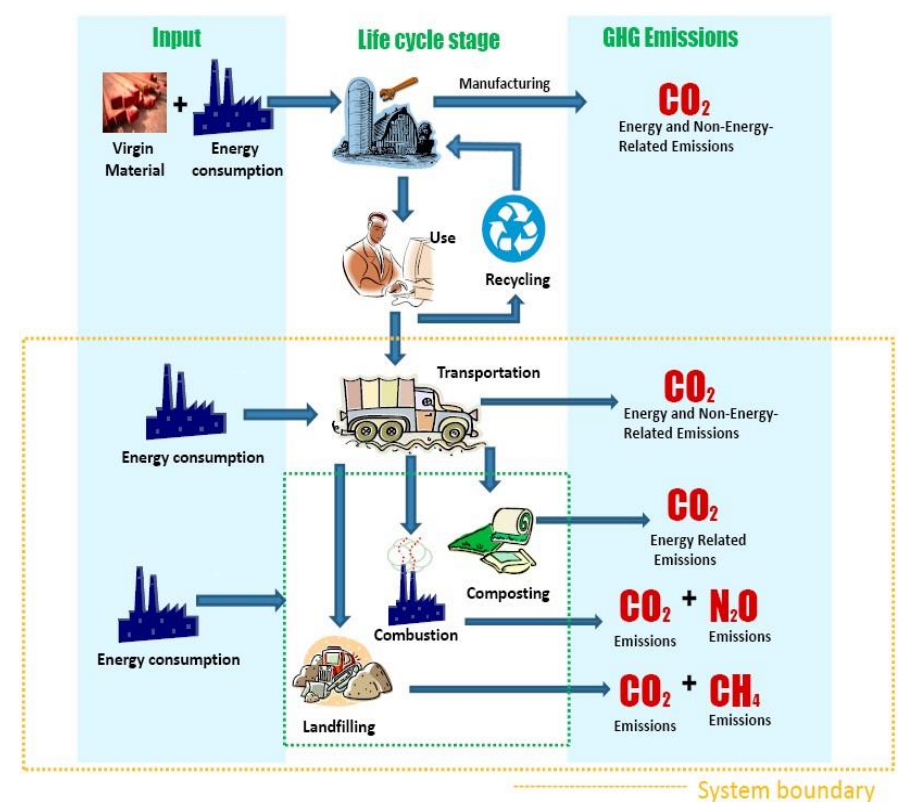

Figure 1. System Boundary

Carbon emission and energy consumption generating during MSW disposal are two critical factors considered by government to make relevant waste disposal policies. In order to develop low-carbon MSWM in Chengdu, the MSW disposal system is introduced and the 
quantitative relationship is discussed. A differential dynamic system model will be given to predict the trend for low-carbon MSWM.

\subsection{System Description}

Low-carbon MSWM system includes five subsystems:energy consumption (energy subsystem), carbon emission (environment subsystem), amount of waste (demand subsystem), disposal cost (economy subsystem), the number of waste disposal facilities (supply subsystem). We will denote them by 5 state variables, and then find the impact factors for these 5 variables. Disposal cost per ton, energy consumption of disposal facilities, number of disposal facilities, supply and demand ratio, and annual per capita disposable income of residents influence the annual variation in amount of waste, annual variation of disposal cost and annual variation of disposal facilities. Generally, annual variation of carbon emission and annual variation of energy consumption in MSWM system are affected only by other subsystems. According to the analysis, two cause effect figures about low-carbon MSWM system are given to show the relationship of these subsystems and factors. In Figure 2, the amount of waste has an impact on disposal cost, and disposal cost(disposal investment) is crucial for the construction and maintenance of disposal facilities, and the renewal of facilities can in turn dispose more waste.



Figure 2. Elements of MSW Disposal Industry

Waste and disposal facilities both result in the carbon emission and energy consumption. In Figure 3, those independent variables, such as GDP, the disposable income of residents and fixed assets all have an impact on the increasing waste generation rate, waste disposal cost and the number of facilities, which influence carbon emission and energy consumption.

\subsection{Index System}

The implication of the main variables and influence factors in this model are listed in Table 1 and Table 2. They are divided into the endogenous and exogenous variable accepted for journal publication. 


\subsection{Mathematical Model}

The series of equations is the foundation of the mathematical model of MSW management system with a fuzzy environment.

The waste generation subsystem is described by the following equation,

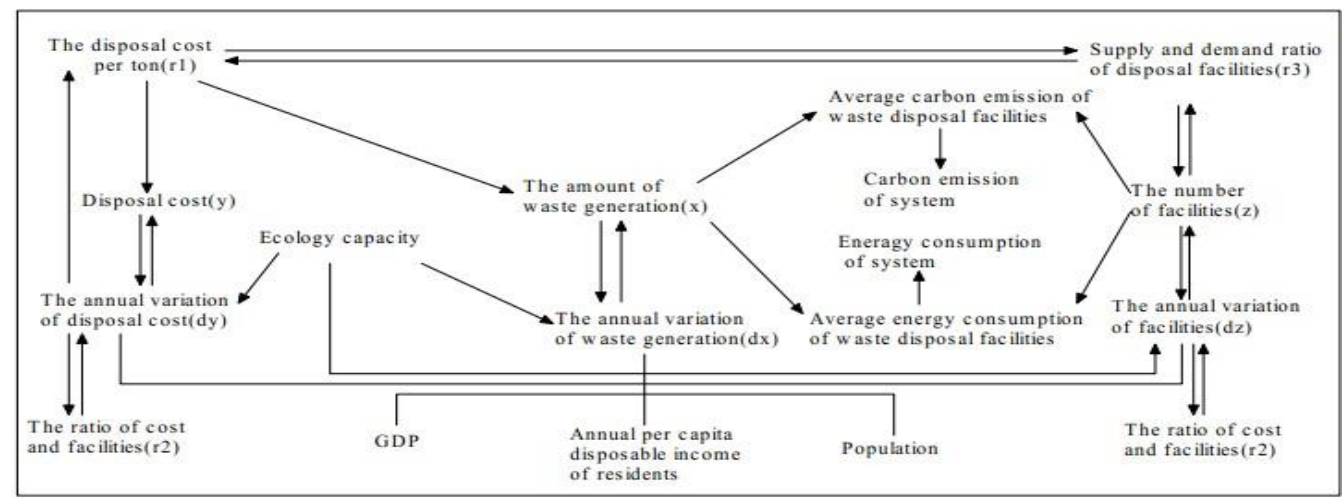

Figure 3. Differential Dynamic Causality Graph

Table 1. Endogenous MSW Management System Variables

\begin{tabular}{clc}
\hline Notation & Variable name & Unit \\
\hline$x$ & amount of waste & $10{ }^{4} T$ \\
$y$ & disposal cost & $10{ }^{4}$ yuan \\
$z$ & number of disposal facilities (includes number of transport carts & $\mathrm{A}$ \\
& number of compression cars and number of compression machines) & \\
$\mathrm{CE}$ & carbon emission of waste disposal & $\mathrm{Kg}$ \\
EC & energy consumption of waste disposal & $\mathrm{MJ}$ \\
$r_{1}$ & disposal cost per ton & no dimension \\
$r_{2}$ & cost to investment of facilities & no dimension \\
$r_{3}$ & facilities of supply to demand & no dimension \\
$e_{1}$ & waste per ton carbon consumption & $\mathrm{Kg}$ \\
$e_{2}$ & average carbon emission of waste disposal facilities & $\mathrm{Kg}$ \\
$e_{3}$ & average energy consumption of waste disposal facilities & $\mathrm{Tce}$ \\
$P$ & population & $\mathrm{A}$ \\
$r_{c}$ & total retail sales of consumer goods & $10{ }^{8}$ yuan \\
$s_{r}$ & annual per capita disposable income of residents & yuan \\
$Q$ & government tourism energy consumption subsidies & $10{ }^{4}$ yuan \\
\hline
\end{tabular}

Table 2. Exogenous MSW Management System Variables

\begin{tabular}{|c|l|c|}
\hline Notation & \multicolumn{1}{|c|}{ Variable name } & Unit \\
\hline$d x$ & annual variation in amount of waste & $10^{4} T$ \\
\hline$d y$ & annual variation in total disposal cost & $10^{4}$ yuan \\
\hline$d z$ & annual variation in disposal facilities & $\mathrm{A}$ \\
\hline$d C E$ & annual emission variation & $\mathrm{Kg}$ \\
\hline$d E C$ & annual energy variation & Tce \\
\hline
\end{tabular}




$$
\frac{d x}{d t}=a x-\bar{\alpha} x
$$

where $\bar{\alpha}$ denotes the variation of the waste generation subsystem restricted by the needs of the local ecology and environmental protection. When the amount of waste grows too fast, the government will take control, such as improve the tax ratio of waste. As a result of different circumstances in different places, the standard of judgment on that growth in the amount of waste exceeding the carrying capacity of the environment is uncertain, thus we introduce fuzzy variable.

The economy subsystem is described by the following equation,

$$
\frac{d y}{d t}=b y-\bar{\beta} y
$$

where $\bar{\beta}$ denotes the improving management approach of MSW. With the development of society, the local government continues to change the way of managing MSW, such as optimize waste transport routes and separate waste collection. In different circumstances, waste disposal approaches used by government are not the same and the effect is uncertain, thus we introduced fuzzy variable.

The facilities subsystem is described by the following equation,

$$
\frac{d z}{d t}=c y-\bar{\gamma} y
$$

where $\bar{\gamma}$ denotes the scarp rate of disposal facilities which is affected by the usage intensity. Because of differing circumstances, the facility's property and the usage frequency are uncertain, thus we introduce a fuzzy variable.

Table 3. Data of the Fuzzy Variables

\begin{tabular}{|c|c|c|c|c|}
\hline $\bar{\alpha}$ & $\bar{\beta}$ & $\bar{\gamma}$ & $\bar{\delta}$ & $\bar{\xi}$ \\
\hline$\left(p_{1}, p_{2}, p_{3}\right)$ & $\left(p_{4}, p_{5}, p_{6}\right)$ & $\left(p_{7}, p_{8}, p_{9}\right)$ & $\left(p_{10}, p_{11}, p_{12}\right)$ & $\left(p_{13}, p_{14}, p_{15}\right)$ \\
\hline
\end{tabular}

The carbon emission subsystem is described by the following equation,

$$
\frac{d C E}{d t}=e_{1} \frac{d x}{d t}+\left(e_{2}-\bar{\delta}\right) \frac{d z}{d t}
$$

where $\bar{\delta}$ denotes the reduction coefficient of MSW disposal facilities. The reduction factors are restricted by some relevant subjective factors, thus we introduce a fuzzy variable.

The energy consumption subsystem is described by the following equations,

$$
\frac{d E C}{d t}=\left(e_{3}-\bar{\zeta}\right) \frac{d z}{d t}
$$

where $\bar{\zeta}$ denotes the energy saving coefficient. The operation of disposal facilities will produce energy consumption, which is controlled by the local government policies and affected by new methods of waste disposal. This kind of saving is restricted by many factors and uncertain, thus we introduce a fuzzy variable.

As shown in Figure 3, GDP, the disposable income of residents and population etc. influence the increasing waste generation, total disposal cost and the number of facilities, 
which affect carbon emission and energy consumption. We assume that the relation between the growth rate and their influence factors is linear.

It follows that

$$
\left\{\begin{array}{l}
\mathrm{a}=\mathrm{a}_{0}+\mathrm{a}_{1} \mathrm{r}_{1}+\mathrm{a}_{2} \mathrm{r}_{3}+\mathrm{a}_{3} \mathrm{p}+\mathrm{a}_{4} \mathrm{r}_{\mathrm{c}}+\mathrm{a}_{5} \mathrm{~s}_{\mathrm{r}} \\
\mathrm{b}=\mathrm{b}_{0}+\mathrm{b}_{1} \mathrm{r}_{1}+\mathrm{b}_{2} \mathrm{r}_{2}+\mathrm{b}_{3} \mathrm{p}+\mathrm{b}_{4} \mathrm{r}_{\mathrm{c}}+\mathrm{b}_{5} \mathrm{~s}_{\mathrm{r}} \\
\mathrm{c}=\mathrm{c}_{0}+\mathrm{c}_{1} \mathrm{r}_{1}+\mathrm{c}_{2} \mathrm{r}_{3}+\mathrm{c}_{3} \mathrm{p}+\mathrm{c}_{4} \mathrm{r}_{\mathrm{c}}+\mathrm{c}_{5} \mathrm{~s}_{\mathrm{r}}
\end{array}\right.
$$

$$
\left\{\begin{array}{l}
\frac{\mathrm{dx}}{\mathrm{dt}}=\mathrm{a}_{0} x+\mathrm{a}_{1} \mathrm{y}+\mathrm{a}_{2} \frac{\mathrm{yx}}{\mathrm{z}}+\mathrm{a}_{3} \mathrm{px}+\mathrm{a}_{4} \mathrm{r}_{\mathrm{c}} x+\mathrm{a}_{5} \mathrm{~s}_{\mathrm{r}} x-\bar{\alpha} x \\
\frac{\mathrm{dy}}{\mathrm{dt}}=\mathrm{b}_{0} y+\mathrm{b}_{1} \frac{\mathrm{y}^{2}}{\mathrm{x}}+\mathrm{b}_{2} \frac{\mathrm{yx}}{\mathrm{z}}+\mathrm{b}_{3} \mathrm{py}+\mathrm{b}_{4} \mathrm{r}_{\mathrm{c}} y+\mathrm{b}_{5} \mathrm{~s}_{\mathrm{r}} y-\bar{\beta} y \\
\frac{\mathrm{dz}}{\mathrm{dt}}=\mathrm{c}_{0} z+\mathrm{c}_{1} \mathrm{y}+\mathrm{c}_{2} \frac{\mathrm{z}^{2}}{\mathrm{x}}+\mathrm{c}_{3} \mathrm{pz}+\mathrm{c}_{4} \mathrm{r}_{\mathrm{c}} z+\mathrm{c}_{5} \mathrm{~s}_{\mathrm{r}} z-\bar{\gamma} z \\
x=x_{0}, y=y_{0}, z=z_{0}
\end{array}\right.
$$

We assume that $\bar{\alpha}, \bar{\beta}$ and $\bar{\gamma}$ are triangular fuzzy numbers shown in Table 3 . The expected value $E[\bar{\alpha}]=\frac{p_{1}+2 p_{2}+p_{3}}{4}$ is considered to convert them into crisp ones. This technique is also applied to $\bar{\beta}, \bar{\gamma}, \bar{\delta}$ and $\bar{\zeta}$.

\section{System Simulation}

\subsection{Data Sources}

The primary data are collected from Chengdu' s statistical yearbook and some other data are provided by Environmental Protection Agency(see Table 4 and Table 5).We use current prices for calculation in the sample data.

Table 4. The Original Database

\begin{tabular}{|c|c|c|c|c|c|c|}
\hline Years & $\begin{array}{c}x \\
\left(10^{4} \text { tons }\right)\end{array}$ & $\begin{array}{c}y \\
\left(10^{4} \text { yuan }\right)\end{array}$ & $\begin{array}{c}z \\
(\mathrm{~A})\end{array}$ & $\left.\begin{array}{c}p \\
\left(10^{4} \text { persons }\right.\end{array}\right)$ & $\begin{array}{c}r_{c} \\
\left(10^{8}{ }^{\text {yuan }}\right)\end{array}$ & $\begin{array}{c}s_{r} \\
(\mathrm{y} \text { uan })\end{array}$ \\
\hline 2001 & 101.32 & 16560.754 & 897 & 1019.90 & 627.52 & 8128 \\
\hline 2002 & 119.27 & 19357.521 & 1032 & 1028.48 & 682.93 & 8972 \\
\hline 2003 & 126.32 & 20332.467 & 1075 & 1044.31 & 771.50 & 9641 \\
\hline 2004 & 133.90 & 21245.913 & 1226 & 1059.69 & 880.76 & 10394 \\
\hline 2005 & 138.40 & 21367.160 & 1127 & 1082.03 & 1005.90 & 11359 \\
\hline 2006 & 152.10 & 23021.856 & 1169 & 1103.40 & 1155.30 & 12789 \\
\hline 2007 & 168.12 & 25402.932 & 1217 & 1112.28 & 1357.20 & 13786 \\
\hline 2008 & 175.67 & 26297.799 & 1297 & 1124.96 & 1621.85 & 16943 \\
\hline 2009 & 193.55 & 28711.207 & 1419 & 1139.63 & 2047.21 & 18659 \\
\hline 2010 & 251.10 & 36396.945 & 1573 & 1149.07 & 2417.57 & 20835 \\
\hline
\end{tabular}

Table 5. The Unit of the Table after Computing a

\begin{tabular}{|c|c|c|c|c|c|c|c|c|c|}
\hline Years & $\mathrm{a}$ & $\mathrm{b}$ & $\mathrm{c}$ & $r_{i}$ & $r_{2}$ & $r_{3}$ & $p$ & $r_{c}$ & $s_{s}$ \\
\hline 2001 & & & & 1 & 0.7979 & 0.966912 & 0.887 & 0.2595 & 0.3901 \\
\hline 2002 & 0.6287 & 0.6596 & 1 & 0.9929 & 0.8106 & 0.945014 & 0.895 & 0.2824 & 0.4306 \\
\hline 2003 & 0.2217 & 0.2080 & 0.29161 & 0.9847 & 0.8174 & 0.929450 & 0.908 & 0.3191 & 0.4627 \\
\hline 2004 & 0.2250 & 0.1861 & 0.93768 & 0.9707 & 0.7489 & 1 & 0.922 & 0.3643 & 0.4989 \\
\hline 2005 & 0.1276 & 0.0241 & 0.60118 & 0.9445 & 0.8193 & 0.889360 & 0.941 & 0.4160 & 0.5452 \\
\hline
\end{tabular}




\begin{tabular}{|c|c|c|c|c|c|c|c|c|c|}
\hline 2006 & 0.3643 & 0.3157 & 0.26138 & 0.9260 & 0.8511 & 0.839412 & 0.960 & 0.4778 & 0.6138 \\
\hline 2007 & 0.3865 & 0.4165 & 0.28745 & 0.9244 & 0.9021 & 0.790608 & 0.967 & 0.5613 & 0.6617 \\
\hline 2008 & 0.1696 & 0.1466 & 0.45469 & 0.9158 & 0.8762 & 0.806366 & 0.979 & 0.6708 & 0.8132 \\
\hline 2009 & 0.3741 & 0.3716 & 0.64184 & 0.9075 & 0.8744 & 0.800717 & 0.991 & 0.8468 & 0.8956 \\
\hline 2010 & 1 & 1 & 0.73545 & 0.8868 & 1 & 0.684182 & 1 & 1 & 1 \\
\hline
\end{tabular}

Table 6. Data of the Fuzzy Variables in LCSD

\begin{tabular}{|c|c|c|c|c|}
\hline $\bar{\alpha}$ & $\bar{\beta}$ & $\bar{\gamma}$ & $\bar{\delta}$ & $\bar{\xi}$ \\
\hline$(0,0.0008,0.002)$ & $(0,0.0008,0.002)$ & $(0,0.0004,0.001)$ & $(0,0.42,0.89)$ & $(0,112.3,178.7)$ \\
\hline
\end{tabular}

Since $a=a_{0}+a_{1} r_{1}+a_{2} r_{3}+a_{3} p+a_{4} r_{c}+a_{5} s_{r}$, a multivariate linear regression should be applied to deal with it. Let $\frac{d x}{d t}=a x$, we can obtain $a=\frac{d x}{x d t}$, and it follows that $a=\frac{\Delta x}{\bar{x}}$, and $\bar{x}=\frac{x_{i}+x_{i+1}}{2}, \Delta x=x_{i+1}-x_{i}(i=0,1,2, \ldots, 10) . b_{0} \sim b_{6}$ and $c_{0} \sim c_{6}$ can be computed by the similar method. SPSS13 software is used to calculate the parameter,

$$
\left\{\begin{array}{l}
\frac{\mathrm{dx}}{\mathrm{dt}}=\left(47.998-30.47+3.129 r_{c}-1.758 s_{r}-\bar{a}\right) x-18.897 \mathrm{y}-1.658 \frac{\mathrm{yx}}{\mathrm{z}} \\
\frac{d y}{d t}=\left(29.643-22.288 p+2.911 r_{c}-1.739 s_{r}-\bar{\beta}\right) y-11.56 \frac{y^{2}}{x}-2.743 \frac{\mathrm{yx}}{\mathrm{z}} \\
\frac{d z}{d t}=\left(-49.627+5.181 p-3.1 r_{c}+6.757 s_{r}-\bar{\gamma}\right) z-24.455 y-25.147 \frac{\mathrm{yx}}{\mathrm{z}} \\
x_{0}=101.32, y_{0}=17541.454, z_{0}=897
\end{array}\right.
$$

As shown in Table 6, we get triangular fuzzy numbers $e_{1}=0.048, e_{2}=2.96$ and $e_{3}=876.8$, which are obtained from National Environmental Protection Bureau and some kinds of fuel Tce conversion published by the National Development and Reform Commission. Finally, we get the following differential dynamic system model,

$$
\begin{aligned}
& \int \frac{\mathrm{dx}}{\mathrm{dt}}=\left(47.998-30.47+3.129 r_{c}-1.758 s_{r}-\bar{a}\right) x-18.897 \mathrm{y}-1.658 \frac{\mathrm{yx}}{\mathrm{z}} \\
& \frac{d y}{d t}=\left(29.643-22.288 p+2.911 r_{c}-1.739 s_{r}-\bar{\beta}\right) y-11.56 \frac{y^{2}}{x}-2.743 \frac{\mathrm{yx}}{\mathrm{z}} \\
& \left\{\frac{d z}{d t}=\left(-49.627+5.181 p-3.1 r_{c}+6.757 s_{r}-\bar{\gamma}\right) z-24.455 y-25.147 \frac{\mathrm{yx}}{\mathrm{z}}\right. \\
& \frac{d C E}{d t}=0.048 \frac{d x}{d t}+2.53 \frac{d z}{d t} \\
& \frac{d E C}{d t}=764.5 \frac{d z}{d t} \\
& x_{0}=101.32, y_{0}-16560.754, z_{0}=897, C E_{0}=3.5 \times 10^{4}, E C_{0}=6.27 \times 10^{5}
\end{aligned}
$$




\subsection{Simulation Model of Chengdu}

Given the complexity of this model, five subsystems are constructed at first, which are the waste generation subsystem, the disposal cost subsystem, the compression facility subsystem, the carbon emission subsystem and the energy-consumption subsystem in MSWM system respectively. Later, those five subsystems are reconstructed into one whole system. Mathematical models used in this simulation are simultaneous equations. The main modules include In, Out, Product, Integrator, Gain, Math function, Scope, etc. Before operating the computer simulation model, $\mathrm{M}$ document is run. We put every parameter in the working space, which is simultaneously activated and used in the working space when operating the simulation model.

\subsection{Simulation Results}

We will check the effectiveness of simulation results from the theoretical analysis and the historical observation. The theoretical analysis is used to check whether those relationships satisfy the theory of MSWM system and whether the overall model is consistent with theoretical analysis and empirical judgment. The historical observation is used to compare simulation results with actual data in MSWM system.

These results show that the amount of waste sharply increases, but disposal cost and facilities have a slower growth. The whole behavior is consistent with theoretical analysis and empirical judgment. From the Figure 4-13 we know the degree of fitting is very high by the proposed method and has the major deviation with the practical value only in 2004. The main reason is that the amount of waste reached the critical condition of maximal disposal capability and the government implemented a series of policies including adding a plenty of advanced disposal facilities. Therefore, it is natural that there are some deviations between the predicted data with the real data. According to the computer simulation, after 2010, MSW generation, disposal cost, disposal facilities will increase year by year and the growth rate of energy consumption and carbon emission in MSWM system increases less than the other three subsystems. At the same time, carbon intensity will be further reduced, which will finally transform to a good situation for the development of low carbon MSWM system.

\subsection{Discussion and Recommendation}

\subsubsection{Analysis of the Change on the Waste Generation}

From the start of simulation to 2006, the total amount of waste generation had a relatively slow growth rate, however, it increased sharply from 2007 to 2010 and peaked 2.511 million tons in 2010. That was because, Chengdu which is a typical western city in China developed slowly and could not compare with those eastern regions at the first several years after 2000, and to a great extent, the amount of MSW generation was limited by the economic factors. With the implement of "eleventh five-year plan" and the grand western development program, the economic growth in western regions, especially in SiChuan Province, was significant and people had more disposable income and extra consumption desire, which lead to a sharp increase in the amount of MSW generation. We find the amount of waste has a high sensitivity to the population of a region, but the population in Chengdu stayed a relatively stable growth rate, therefore, economic factors such as GDP, total retail sales of consumer goods,annual per capita disposable income of residents play a more important role in waste generation. 
With economic growth and population gains, MSW generation keeps a fast growth and will reach 6.5 million tons in 2030. When the economy reaches a high level in 2030, the economy structure will change a lot, for example, the proportion of service consumption such as education, information, culture etc. will be getting large, and this kind of consumption produces very little or even none MSW, therefore, the MSW growth rate slows down after 2030. Due to the policy of source waste reduction and separate collection implements deeply, the MSW generation will reach the stable state in 2045 and decline slightly on that basis.

MSW should be effectively controlled to prevent it from causing environment pollution and ecological destruction. The government could take several policies to improve the situation of MSW generation control. MSW fee system can be built according to the amount of MSW and its relevant disposal cost, and to some extent, it will reduce the MSW generation. The implementation of waste classified management including separate waste collection, transportation and disposal is an important way to control municipal solid waste. The government should also cultivate the awareness of environmental protection to let citizens actively cooperate with MSW reduction implementation.

\subsubsection{Analysis of the Change on the Disposal Cost}

Because of the growing amount of MSW, the disposal cost increased year by year, which reached 363.96 million yuan in 2010. There are several reasons that lead to the high growth rate of MSW disposal cost. For developing low-carbon MSW management system, a large amount of money was used to reduce carbon emission. As the slow progress of disposal technology in western China, secondary pollution is serious and costs a lot to deal with this problem such as landfill leachate and toxic gas emission. Therefore, from 2002 to 2010, the growth rate of MSW disposal cost stayed a high level, and higher than that of the amount of the MSW generation.

The disposal cost of MSWM system closely connects with the waste amount, and due to the replacement of outdated disposal facilities and investment of MSW management system such as adding management agencies, it keeps a high growth rate before 2030. After 2030, as the growth rate of MSW generation significantly slows down, the total disposal cost has a tendency of sluggish increase.

For reducing carbon emission and greenhouse gas emission during the whole life cycle of MSWM system, a large extra sum of money is necessary and inevitable to achieve this goal. As MSW disposal budget is limited and restricted, conservative measures should be taken to cut down the cost. Separate collection and MSW recycling are two effective ways to reduce disposal cost, turning waste into available materials and directly avoiding environmental destruction, which makes profits from MSW. On the other way, MSW disposal programming such as computing the waste transportation routes, making the waste disposal plans in different time, can be used to reduce disposal cost.

\subsubsection{Analysis of the Change on the Disposal Facilities}

Because of the impact of Nanqiao garbage compressed transfer station constructed in 2004, which was the largest garbage compressed transfer station in China and associated with a lot of separate collecting garbage trucks and transport carts, the disposal facilities reached 1226. But it decreased to 1127 the next year due to the destruction of many old waste transfer stations and disposal facilities. After 2005, disposal facilities increased significantly which was related to the large MSW generation and the need of low-carbon objection. In 2010, with the refreshment of old facilities, there are $1573 \mathrm{MSW}$ disposal facilities in Chengdu. 
Based on the overall analysis in the change of different kinds of disposal facilities, from 2002 to 2030, in Chengdu, it is a growth period for disposal facilities. Since then, however, we see the growth rate of disposal facilities slows down. That means, after the refreshment of old disposal facilities, the MSWM system is getting stable and will enter the positive circulation stage.

The next Chengdu government should pay more attention to the number of disposal facilities which ensure low-carbon MSWM system develop and keep carbon emission staying in a low level. New disposal facilities should achieve "Green Facility" assessment standards, which means low pollute emission and energy consumption. Mathematical programming model can be built by authorities to determine how many facilities would be associated with different transfer station and meet the need of waste disposal.

\subsubsection{Analysis of the Change on the Carbon Emission}

From the simulation start to the end, the total carbon emission of the Chengdu's MSWM system was rising, but the growth was slow, and lower than that of the number of waste generation and disposal facilities. Since then, the carbon emission growth rate is getting slower, which is related to the low-carbon policy of MSWM system.



Figure 4. Model Check of Waste Generation



Figure 6. Model Check of Disposal Cost



Figure 5. Prediction of Waste Generation

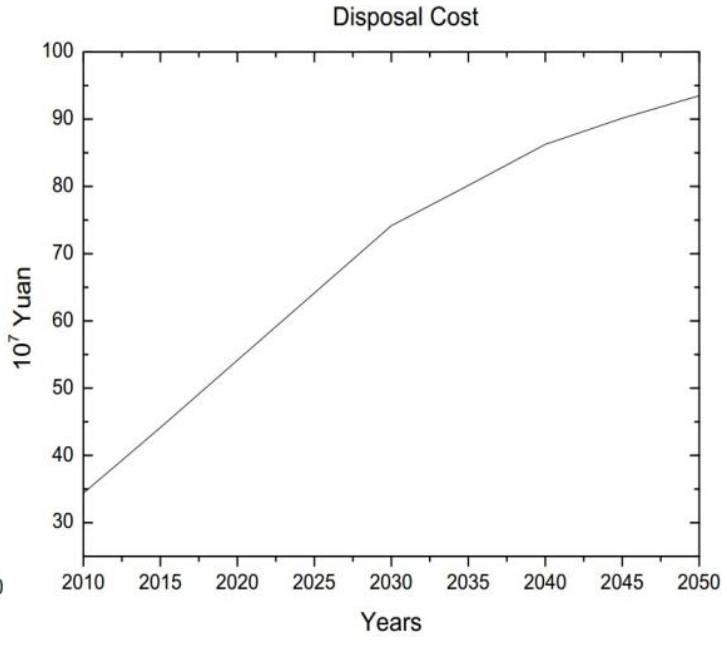

Figure 7. Prediction of Disposal Cost 


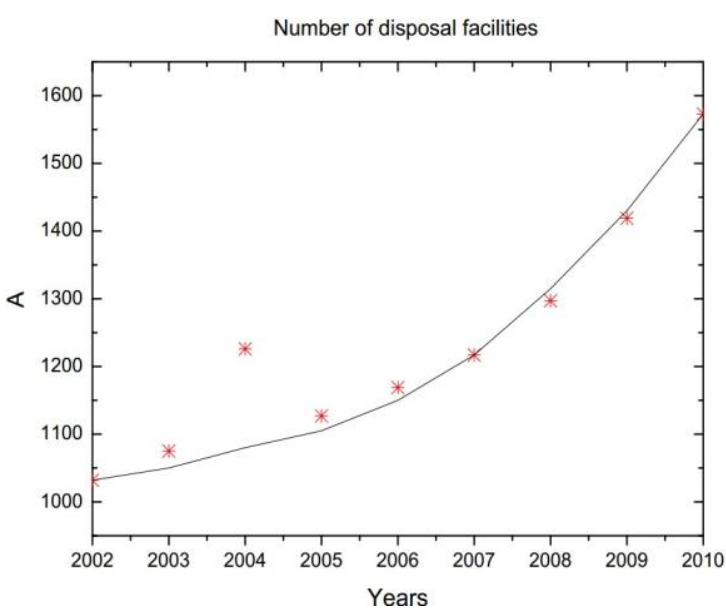

Figure 8. Model Check of Disposal Facilities

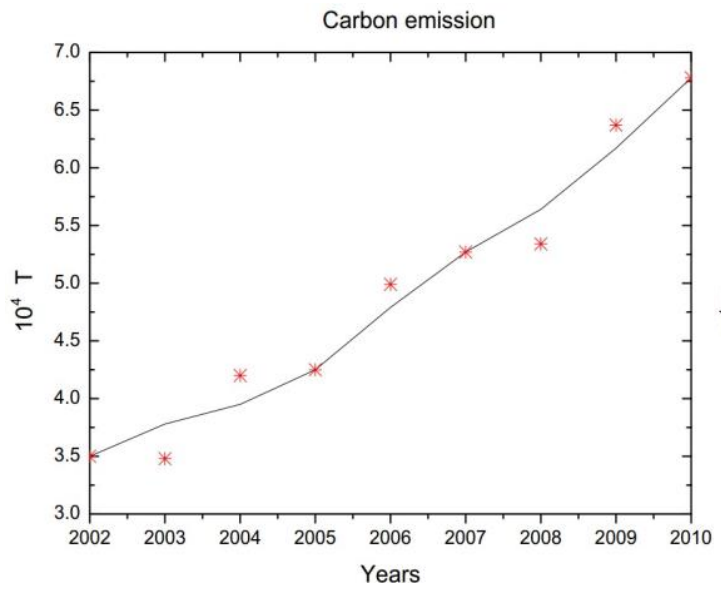

Figure 10. Model Check of Carbon Emissions



Figure 12. Model Check of Energy Consumption

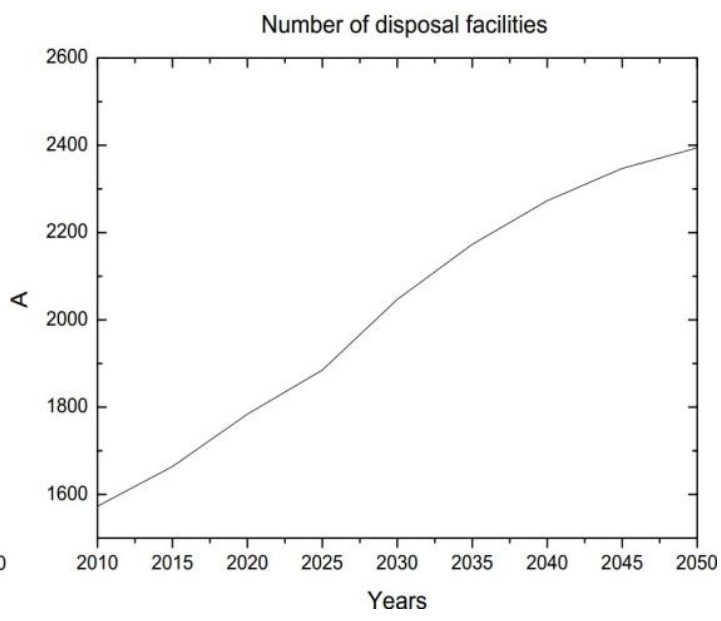

Figure 9. Prediction of Disposal Cost



Figure 11. Prediction of Carbon Emissions

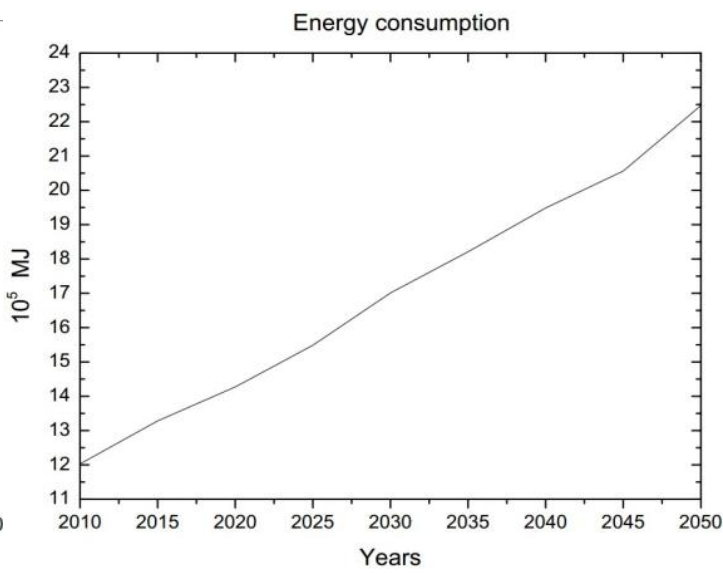

Figure 13. Prediction of Energy Consumption 
The main practice for reducing carbon emissions from waste management is the cap-ture and combustion of landfill gas, with energy recovery where practical. However, materials recycling and composting prior to landfill is being established in Chengdu. Materials recycling and composting is higher up the waste hierarchy (prevent/minimize; prepare to reuse; recycle and compost; recover; then dispose). Waste recycling and composting should provide more emission reductions than collection and combustion of landfill gas with energy use (e.g., electricity generation), as the landfill gas is pre-vented from being generated, rather than around 50\% of the gas being recovered and combusted. The reuse of products and the recycling of materials provide emission reductions against the manufacture of new materials from virgin sources. Recycling and composting should therefore provide more carbon emission reductions and potential low-carbon MSWM system income than landfill gas combustion with energy recovery. Authorities of Chengdu needs to implement practical, lowcarbon disposal indicators and measures, and finally construct a chain for the low-carbon development of MSWM system.

\subsubsection{Analysis of the Change on the Energy Consumption}

From the simulation start to 2010, the total energy consumption of Chengdu's low-carbon MSWM system was rising, but the growth was slow, and lower than that of waste generation and facilities. It shows that the energy consumption growth rate is in the normal range while the amount of waste generation grows fast. At the atmosphere of low-carbon concept, this system not only brings low-carbon emission but also decreases the total energy consumption by seeing the tendency from 2011 to 2050 .

MSW disposal is a high energy consumption industry which needs a huge amount of electricity and power fuel. The route of MSW transportation should be well planned because that effective route programming can contribute to less kilometers and time saving, leading to fewer energy consumption. New energy disposal equipment and energy saving technology would also be taken into consideration to reduce energy consumption. The City District needs to focus on energy consumption during the course of MSW disposal so that the low-carbon MSWM system can be developed.

\subsubsection{Conclusions}

This paper aims to apply differential dynamic system model to predict the low-carbon MSWM system. Five subsystems are integrated into a comprehensive disposal system. Their quantitative relationships are discussed. By using SPSS 13.0 to fit the parameters in each subsystem in low-carbon MSWM system differential dynamics, we obtain a series of fuzzy differential equations. Finally, some analysis and suggestions are given to develop the lowcarbon MSWM system.

In the current discussion on differential dynamics to construct a low-carbon disposal system with fuzzy coefficients, the analysis often focuses on the interaction among the subsystems of waste generations, cost, disposal facilities, carbon emission and energy consumption. This reference fuzzy coefficient only takes into consideration the impact of government regulation and ignores the limitations of consumption, energy-saving technology and other subjective factors, which will be studied in depth in future research.

\section{Acknowledgements}

The authors would like to thank the anonymous referees for their insightful comments and suggestions to improve this paper. This work was financially supported by the Foundation of Sichuan Center For Rural Development Research (No.CR1320). 


\section{References}

[1] Z. Li, "Quantitative analysis of sustainable energy strategies in China”, Energy Policy, vol. 38, (2010), pp. 2149-2160.

[2] J. L. Hu and Y. C. Lee, "Efficiency three industrial waste abatements for regions in China", International Journal of Sustainable Development and World Ecology, vol. 15, no. 1, (2008), pp. 132-144.

[3] R. Vijay, A. Gautam, A. Kalamdhad, A. Gupta and S. Devotta, "GIS-based locational analysis of collection bins in municipal solid waste man-agement systems", Journal of Environmental Engineering and Science, vol. 7, no. 1, (2008), pp. 39-43.

[4] N. V. Karadimas, K. Papatzelou and V. G. Loumos, "Genetic al-gorithms for municipal solid waste collection and routing optimization", Artificial Intelligence and Innovations 2007: From Theory to Applications, (2007), pp. 223-231.

[5] S. Yedla and J. K. Parikh, "Economic evaluation of a landfill system with gas recovery for municipal solid waste management: a case study", International Journal of Environment and Pollution, vol. 15, no. 4, (2001), pp. 433-438.

[6] X. Guo, J. Kulczycka, K. Koneczny and D. Li, "Web-based DSS for economic evaluation of municipal solid waste management", EEESD '07: Proceedings of the 3rd IASME/WSEAS International Conference on Energy, En-vironment, Ecosystems and Sustainable Development, (2007), pp. 30-35.

[7] E. Daskalopoulos, O. Badr and S. D. Probert, "Economic and environmental evaluations of waste treatment and disposal technologies for municipal solid waste", Applied Energy, vol. 58, no. 4, (1997), pp. 209-255.

[8] D. Ozeler, U. Yetis and G. N. Demirer, "Life cycle assesment of municipal solid waste management methods: Ankara case study", Environment International, vol. 32, no. 3, (2006), pp. 405-411.

[9] M. D. Bovea, V. Ibanez-Fores, A. Gallardo and F. J. Colomer-Mendoza, "Environ-mental assessment of alternative municipal solid waste management strategies", A Spanish case study. Waste Management, vol. 30, no. 11, (2010), pp. 2383-2395.

[10] K. Naushad, F. Huan and Y. Danlin, "A system dynamic modeling ap-proach for evaluating municipal solid waste generation, landfill capacity and related cost management issues", Waste Management, vol. 30, (2010), pp. 2194-2203.

[11] S. Muehle, I. Balsam and C. R. Cheeseman, "Comparison of carbon emissions associated with municipal solid waste management in Germany and the UK", Resources Conservation and Recycling, vol. 54, no. 11, (2010), pp. 793-801.

[12] K. G. Pikon, "Greenhouse Gas Emission Mitigation Relevant to Changes in Municipal Solid Waste Management System", Journal of the Air \& Waste Management Association, vol. 60, no. 7, (2010), pp. 6188.

[13] V. L. J. Hale, "Introduction to functional differential equations", Springer, New York, (1993).

[14] J. Park, "Design of dynamic controller for neutral differential systems with delay in control input", Chaos, Solitons \& Fractals, vol. 23, (2005), pp. 503-509.

[15] J. Park, "Robust guaranteed cost control for uncertain linear differential systems of neutral type", Applied Mathematics and Computation, vol. 140, (2003), pp. 523-535.

[16] J. Park and O. Kwon, "Lmi approach to robust filtering for neutral delay differential systems", Applied Mathematics and Computation, vol. 150, (2004), pp. 235-244.

[17] O. Kaleva, "Fuzzy differential equations", Fuzzy Sets and Systems, vol. 24, (1987), pp. 301-317.

[18] S. Seikkala, "On the fuzzy initial value problem", Fuzzy Sets and Systems, vol. 24, (1987), pp. 319-330.

[19] E. Hullermeier, "Approach to modeling and simulation of uncertain dynamical systems", International Journal of Uncertainty, Fuzziness and Knowledge-Based Systems, vol. 5, (1997), pp. 117-137.

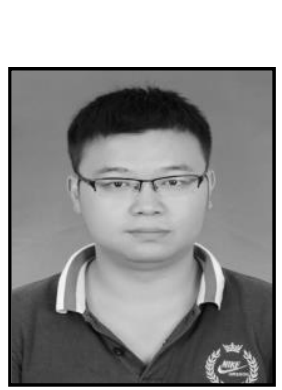

\section{Author}

Yunqiang Liu received the Ph.D. degree from Sichuan University, major in Management Science and Technology in 2013. He is currently a lecturer in College of Economics \& Management at Sichuan Agricultural University. His research interests are in the areas of mathematical modeling, differential dynamic system and urbanization research. 